\title{
Sustainable Development Through Green-Themed Environmental Impact Assessment: Lessons for Developing Countries
}

\author{
Nonso Izuchukwu Ewurum ${ }^{1} \quad$ Paul Chuks Anih ${ }^{2} \quad$ Kenechi Peter Ifeanacho ${ }^{1}$ \\ 1.Estate Management, University of Nigeria Nsukka, Enugu, Nigeria \\ 2.Estate Management, University of Uyo, Akwa Ibom, Nigeria
}

\begin{abstract}
In this study, we used Geographic Information System and remote sensing to explore the stimulation of sustainable development through "Green-Conscious" Environmental Impact Assessment of industrial projects. Despite the global clamour for sustainable development as panacea for recent climatic concerns; sustainable development initiatives like Nano and green technologies are not highlighted in key Sections of the Nigerian EIAAct. The study adopted time series of 16-day composite Moderate Resolution Imaging Spectroradiometer 250m resolution NDVI data (MOD13Q1) covering South West, Nigeria between 2002-2017. We conclude that Nigeria cannot attain sustainable development if relevant laws are not amended to include sustainability initiatives.
\end{abstract}

Keywords: Sustainable Development; Going-Green; Environmental Impact Assessment; EIA; Industrial Projects, Nanotechnology

DOI: $10.7176 /$ JEES/10-5-06

Publication date:May $31^{\text {st }} 2020$

\section{Introduction}

The economic success story that China has become today has partly, if not mostly, inspired a paradigm shift towards an export-oriented focus that seeks to transcend emerging economies from primary to secondary sectors. Central to this philosophy is the revitalization of the manufacturing industry to promote the development of other sectors and rejuvenate the economy through improvements in Foreign Direct Investment, economic diversification, and further reduction of unemployment (Ajayi, 2011). Despite these prospects, the manufacturing industry also offers a myriad of challenges for developing nations like Nigeria, still grappling with poor recycling and waste management strategies (Ndubuisi-Okolo, 2016). Thus, in the production of desirable goods, the industry has also produced harmful substances as industrial wastes, with negative externalities such as global warming, ozone layer depletion, food insecurity, deforestation, depletion of fishes and wildlife to mention a few.

This is in stark contradiction of the 2015 United Nations Sustainable Development Goals on "catalysing renewed national policy development and international cooperation and support for sustainable development". Obviously, there are measures already in place to avert such externalities globally, and one of such measures is the conduct of Environmental Impact Assessment (EIA). In the review of EIA and enabling laws, the paper x-rays global and indigenous EIA Acts, practices and performance; impact of private industrial projects on the environment under the purview of the EIA Act in Nigeria, and applicability of going green in EIA of private industrial projects.

\subsection{Study Area}

Over the years, the Nigerian industrial sector comprises oil, telecommunication, construction among others. It is however, noticeable that the pattern of the distribution of private manufacturing industries at the city level indicates that there is marked concentration of manufacturing establishments in the Southern part of the Country especially Lagos, Abeokuta and Ibadan. As a result, this part of Nigeria formed the area of the study. The area under investigation is South-Western region of Nigeria which lies between longitude $2^{\circ} 31^{\prime}$ and $6^{\circ} 00^{\prime}$ East and Latitude $6^{\circ} 21^{\prime}$ and $8^{\circ} 37^{\prime} \mathrm{N}$ (Figure 1), and comprises of six states including Lagos, Ogun, Oyo, Osun, Ondo and Ekiti states. It covers a total land area of 77,818 km2 (FORMECU, 1998), and is bounded on the north by North-Central region, on the east by South-East and South-South regions, on the south by Atlantic Ocean, and on the west by the Republic of Benin. The South-western Nigeria is a typical tropical environment with temperature ranges of between $21^{\circ} \mathrm{C}$ and $34^{\circ} \mathrm{C}$, while the annual rainfall ranged between 150 and $3000 \mathrm{~mm}$. 


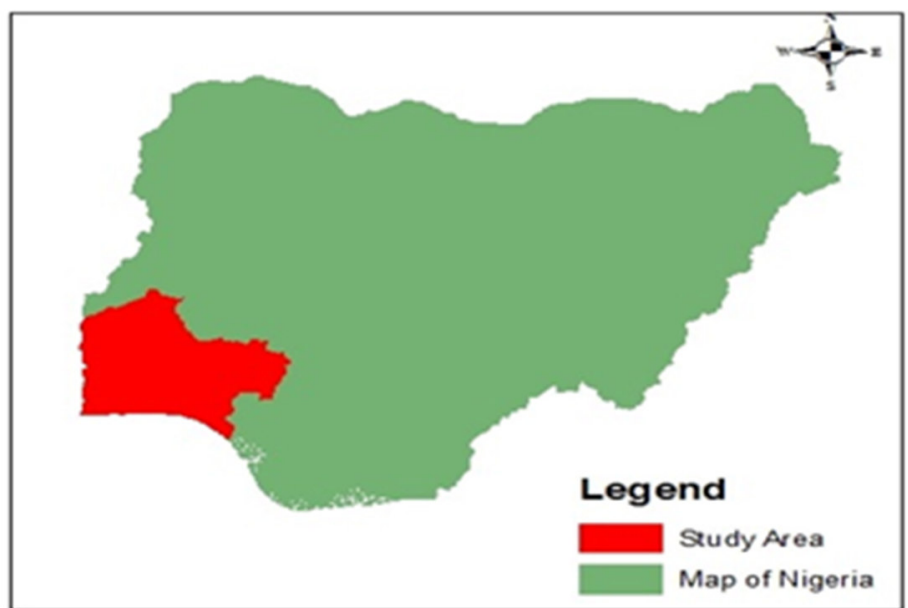

Figure 1: Map of Nigeria Showing Location of the Study Area

\section{Review of Related Literature}

\subsection{Environmental Impact Assessment: An Overview}

Razali, Zainudin and Mei (2017) aver that The Rio Earth Summit event in 1995 was one of the first steps taken to control the environmental impact from development activities around the world. The Kyoto agreement, endorsed by 150 countries, was a commitment by these countries to reduce their emissions from development activities through the introduction of a sustainable development plan as their countries' main policy to control the impact of industrial developments on the environment (Razali et al., 2017). Accordingly, the generic process of project-level Environmental Impact Assessment (EIA) was institutionalized in the United States (US) as a requirement of the country's "National Environmental Policy Act of 1969" (NEPA) which was signed into law at the beginning of 1970 (Nwafor, 2006). Prior to 1970, project and policy appraisals were based largely on technical and cost-benefit analyses.

In over four and half decades of its existence, project-level EIA has evolved considerably in scope, tools, techniques and methodology. Meanwhile, the generic aspects which characterize all impact assessment work such as public participation or involvement, screening and scoping, impact identification, prediction, monitoring and evaluation have persisted. Environmental Impact Assessment (EIA) is carried out to identify, predict and to describe in appropriate terms the pros and cons (penalties and benefits) of a proposed development (United Nations Environment Protection, 1978). The International Association for Impact Assessment (IAIA) defines an environmental impact assessment as "the process of identifying, predicting, evaluating and mitigating the biophysical, social, and other relevant effects of development proposals prior to major decisions being taken and commitments made." We agree with this EIA conceptualization.

Consequently, EIA is targeted at effective decision making and constitutes a preventive measure. The implication is that for EIA to be successful, the assessment needs to be communicated in terms understandable by the community and decision-makers; and the pros and cons identified on the basis of criteria relevant to the countries affected. Lending credence, Ewurum et al (2018) describe EIA as a process having the ultimate objective of providing decision-makers with an indication of the likely consequences of their actions. Globally, there has been widespread adoption of EIA but also a number of adaptations. Weaver (2008) observed that notable adaptations include a "shift from the focus on biophysical aspects, to the inclusion of social and economic issues; the inclusion of implementation aspects (such as environmental management plans); attempts to address sustainability issues such as biodiversity loss and cumulative effects; application to higher levers of decisionmaking such as plans, policies and programmes".

The process involves several activities that may vary from country to country. However, the generic activities as articulated by United Nations Environment Protection (UNEP, 2002) are as follows in Figure 2: 


\section{Generalised EIA Process Flowchart}

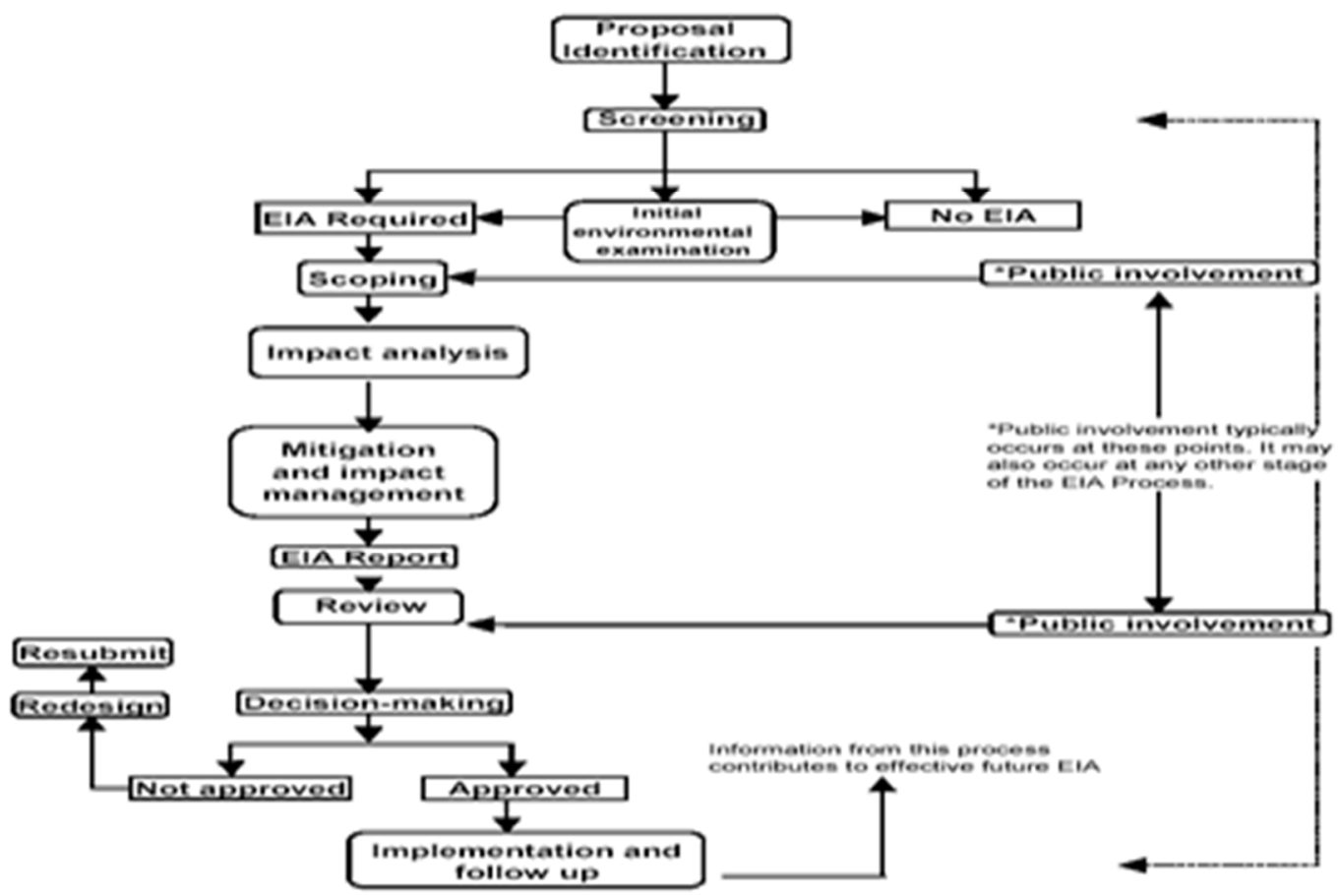

Figure 2: General framework for EIA (UNEP, 2002).

Figure 2 shows that the EIA framework comprises several steps which boil down to proper description of the project and the environment, identification and evaluation of environmental impacts; and good management and control of the identified impacts. The paper examines, in the next section, the applicability of EIA globally and indigenously.

\subsection{EIA of Private Projects: Global Report}

\section{A. United States}

In the United States, the National Environmental Policy Act (NEPA) 42 U.S.C. 4321-4347 established a policy of Environmental Impact Assessment (EIA) with the mandate of reducing the impact of toxic industrial wastes on the environment through source reduction, recycling/reuse, and treatment. The result is the enhanced protection of human health, cleaner environment, cost savings, and higher product quality (EPA, 2018).

\section{B. Europe}

In Europe, the European Commission on Environment policy framework presents varied strategies to curb industrial waste as contained in its Guidelines for Waste Prevention Programme (European Commission on Environment, 2018). The strategies include the EU Sustainable Development Strategy (SDS, 2006), the Sixth Environmental Action Programme (6EAP, 2002-2012), and Sustainable Industrial Policy (SIP) (2008) which mandates members to evaluate the suitability of national waste prevention programmes, establish and develop product re-use and repair networks, review and revise waste prevention programmes at least every six years. This is characteristic of the Town and Country Planning (Environmental Impact Assessment) Regulations 2017 of England.

\section{China}

Interestingly, Article 1 of Law of the People's Republic of China on Environmental Impact Assessment states that the Law is formulated for the purpose of implementing the strategy of sustainable development, preventing adverse impact on the environment due to execution of plans and construction projects, and facilitating the coordinated development of the economy, the society and the environment. By implication, the key feature of the Law is the goal of attaining sustainable development, which the 65th Assembly of the United Nations General Assembly describes as the guiding principle for long-term global development.

A perusal of the United States, Europe and China EIA Laws confirms sustainable development as the dominant theme in EIA, with the US and EU laws emphasizing the prospects of reuse, reduce and recycle system which is consistent with the United Nations "Green Economy Initiative" (see UN Sustainable Development Goals, 
2015). In consistence with the sustainability theme of the 2015 UN Sustainable Development Goals, United Nations Systems in 2016 in a bid to stress the narrative, commissioned the United Nations Environmental Protection as the lead agency in achieving Green Economy Initiative (GEI) as "response to the development challenges and imbalances in growth strategies that underlie the global financial and economic crisis by motivating policymakers in all countries to give green investments sufficient space in their counter-cyclical policies, and thus reduce the threat of further food, water, energy, ecosystem and climate crises, which have disproportionate impacts on the poor."

\section{Africa}

Disturbingly, this global evolution seems lost on African countries, and has rendered the EIA Laws in many African countries archaic and obsolete. The Environmental Impact Assessment Regulations (Government Notice No. R.543 of June 18, 2010 - corrected by Government Notice No. R.660 of July 30, 2010 and Government Notice No. R.1159 of December 10, 2010) of South Africa, and the Environmental Assessment Regulations 1999 of Ghana are yet to incorporate sustainability development initiatives.

\subsection{Nigeria: Legal framework for EIA}

In Nigeria, the Environmental Impact Assessment is regulated by EIA Decree no 86 of 1992 now Cap. E12 LFN 2004. EIA requires that environmental impact considerations be included in project planning and delivery. The thrust of the Decree is to ensure that balanced decision making occurs in the total public interest. However, the same issues bedeviling EIA in African countries is applicable to Cap. E12 LFN 2004 (originally Decree No. 86 of 1992), which is the enabling Law for Environmental Impact Assessment (EIA) in Nigeria. Schedule to Section 12 of the Act aptly captures industrial project as one requiring such "Assessment in its Mandatory Study List", while Section 2 of the Act prohibits public or private sector of the economy from undertaking projects or activities without an environmental impact assessment which shall be undertaken in accordance with the provisions of the Act.

\section{A. Observations}

The sustainable development and green economy initiative which are fixtures of EIA laws in advanced economies are not yet embedded in Sections 1 and 4 of the Act which center on the "Goals" and "Minimum Content of Environmental Impact Assessment Report". This lacuna becomes conspicuous given that Nigeria is a signatory of the UN's 2015 Sustainable Development Goals. The implication is that the current EIA Law in Nigeria does not explicitly promote energy efficient technologies, renewable energy, sustainable agriculture, environment and ecofriendly tourism, and sustainable management of natural resources including ecosystems and biodiversity. When these are incorporated into the EIA Law, there is a better chance for economic recovery and sustainable growth, increased competitiveness, improved employment opportunities, and poverty alleviation (UN Systems, 2016). To buttress this fact, it behooves upon us to examine the performance of the present EIA Act in Nigeria.

\section{Methodology}

The study investigated and monitored land use and land cover using remote sensing, which requires images of different epoch, in a bid to determine the impact of private industrial projects on the environment. Thus, a time series of 16-day composite MODIS (Moderate Resolution Imaging Spectroradiometer) 250m resolution NDVI data (MOD13Q1) covering locations where private industrial projects are cited in the study area was downloaded from the earth observing system data gateway for the period of 2002-2017 at five years' interval. The satellite data was acquired for same season because it was envisaged that, use of images for different months would undermine the comparison of classification results (Mfitumukiza, 2014). The MODIS (Moderate Resolution Imaging Spectroradiometer) is a key instrument aboard the NASA's Terra and Aqua satellites. The two satellites acquire images of the entire earth surface every one to two days (Nwosu and Ugwuoti, 2011) in 36 spectral bands between 0.405 and $14.385 \mathrm{~m}$ which can be used to produce NDVI imagery at 250,500 , and $1000 \mathrm{~m}$ resolution.

\subsection{Classification of MODIS Datasets}

A suitable classification system and a sufficient number of training samples are prerequisites for a successful classification (Lu and Weng, 2007). Developing a classification system involves selecting criteria for defining and differentiating categories. This depends on several factors including purpose of classification, and number of attributes used to assign an object to a group, etc. The classification scheme adopted in the current study is based on physiognomic categories, and comprise of sparse vegetation, mild vegetation, and dense vegetation.

The intent of the classification procedure is to categorize all pixels in a digital image into one of numerous land cover classes, or "themes" (Omali, 2018). Based on their spectral signatures, the MODIS image pixels covering the study area were organized into a finite set of classes that distinguished unique surface types. Subsequently, the ISODATA unsupervised classification technique was used to classify the vegetation cover of areas where private industrial projects are located.

Investigating and monitoring the condition of the earth surface is a critical requisite for change study at local, 
regional and global scale. Terrestrial vegetation is a significant component of the earth surface, and has had an active role in influencing the ecological systems of the world, and plays an important role in energy exchange, biogeochemical and hydrological cycling processes on the land surface as an "indicator" for studying global changes (Kutiel, Cohen, Shoshany, Shub, 2004). Vegetation is a broad expression for plant ecosystem on the terrestrial surface, especially, forests, and rangeland resources (Okeke and Omali, 2016). Therefore, vegetation mapping presents valuable information for understanding natural and man-made environments (Saini, and Ghosh, 2018) using techniques such as detailed field surveys of all the vegetation in a district, and remote sensing which offers a practical and economical means to study vegetation cover changes, especially over large areas (Nordberg and Evertson, 2003).

Remote sensing images are used to extract the vegetation information based on distinctive spectral and textural features (Wood, Pidgeon, Radeloff and Keuler,2012). Because of the prospective facility for methodical observations at diverse scales, remote sensing technology extends potential data collection from present time to over several decades in the past. For this advantage, enormous efforts have been made by researchers and application specialists to delineate vegetation cover from local scale to global scale by applying remote sensing imagery (IGBP, 1992; JRI, 1999; and NASA; 2001). Besides these datasets at the global and continental scales, there have also been numerous efforts taken over regional or national extents to map vegetation (Ochege and Okpala-Okaka, 2017; Saini et al., 2018). The present study is another effort with similar intention by utilizing satellite data to map and monitor vegetation cover of tropical ecosystem, with specific focus in the South-Western region of Nigeria from 2002-2017; in a bid to determine the impact of private industrial projects on the environment using vegetation and temperature as proxies.

\section{Results, Analysis and Discussion}

The unsupervised classification maps, showing the spatial extent and variations in vegetation cover across the study area, are presented in Figures 3, 4, 5, and 6. For effective visual interpretation, suitable colour patterns have been used to identify and show the various classes. Spruce green represents dense vegetation, lemon grass represents mild vegetation, mars red represents sparse vegetation, while lapis lazuli is used to represent nonvegetated areas.

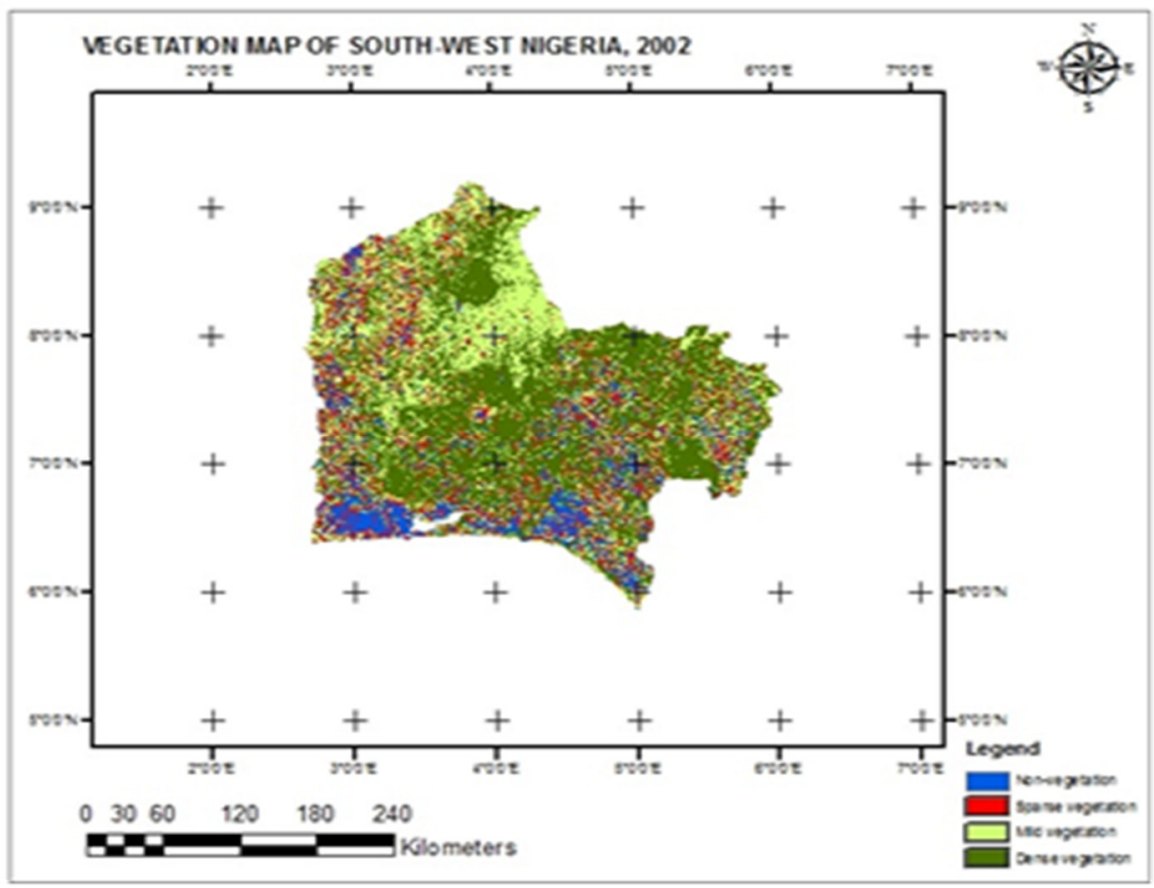

Figure 3: Vegetation map of South-West Nigeria, 2002. 


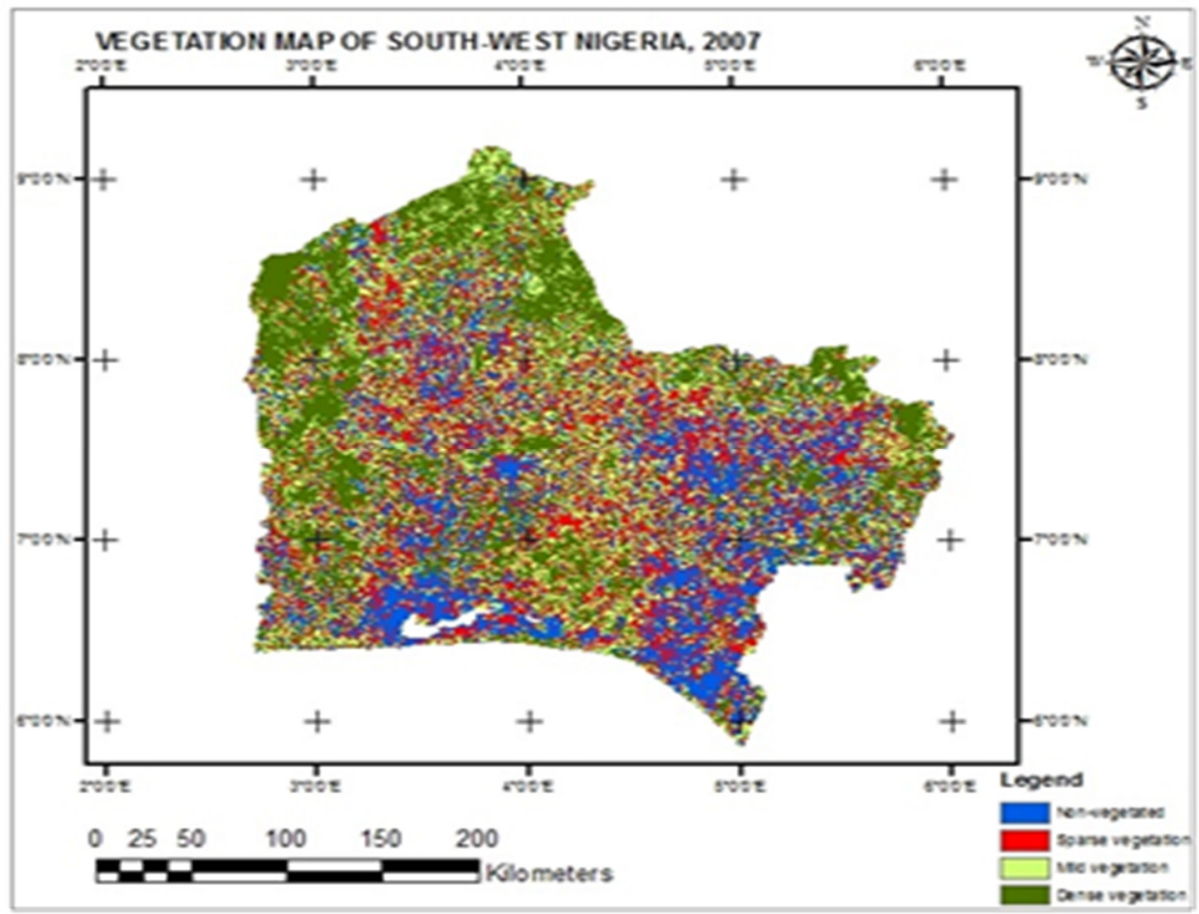

Figure 4: Vegetation map of South-West Nigeria, 2007.

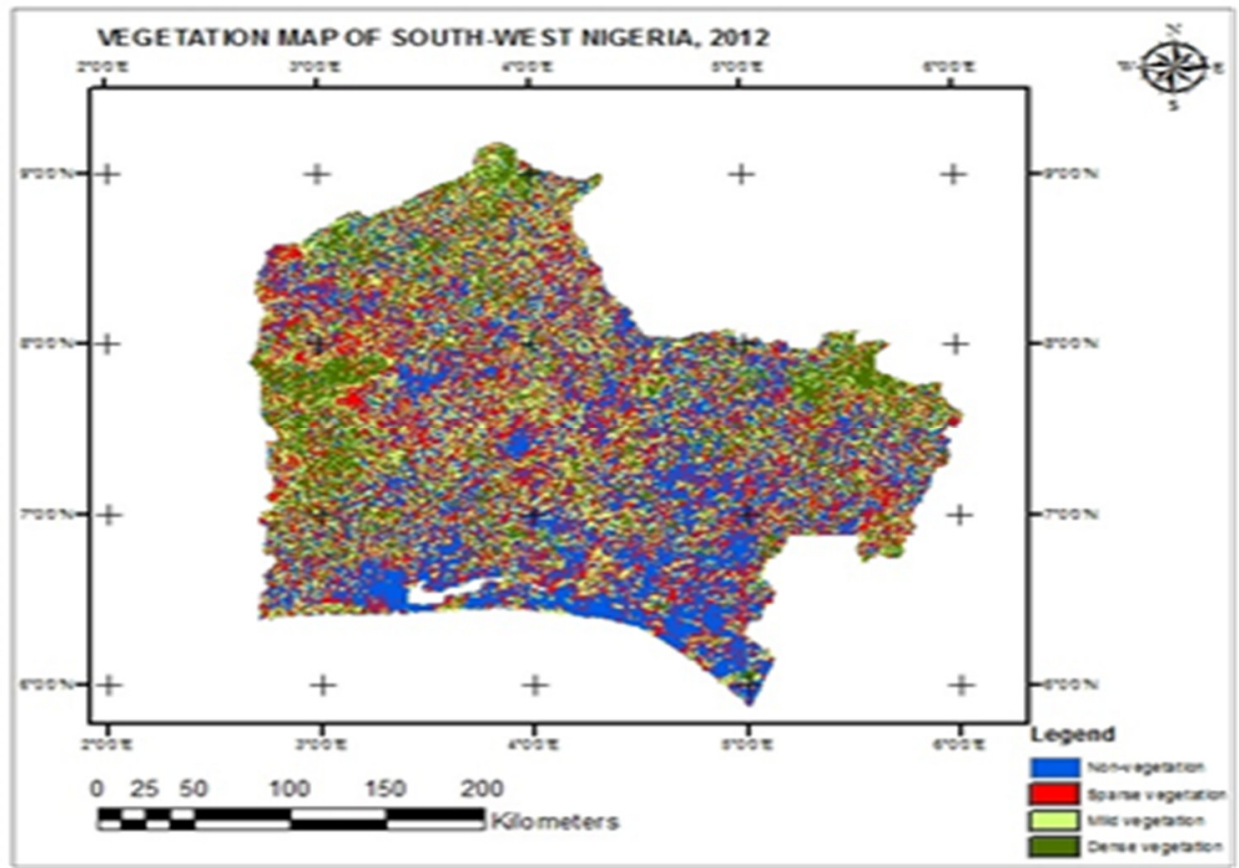

Figure 5: Vegetation map of South-West Nigeria, 2012. 


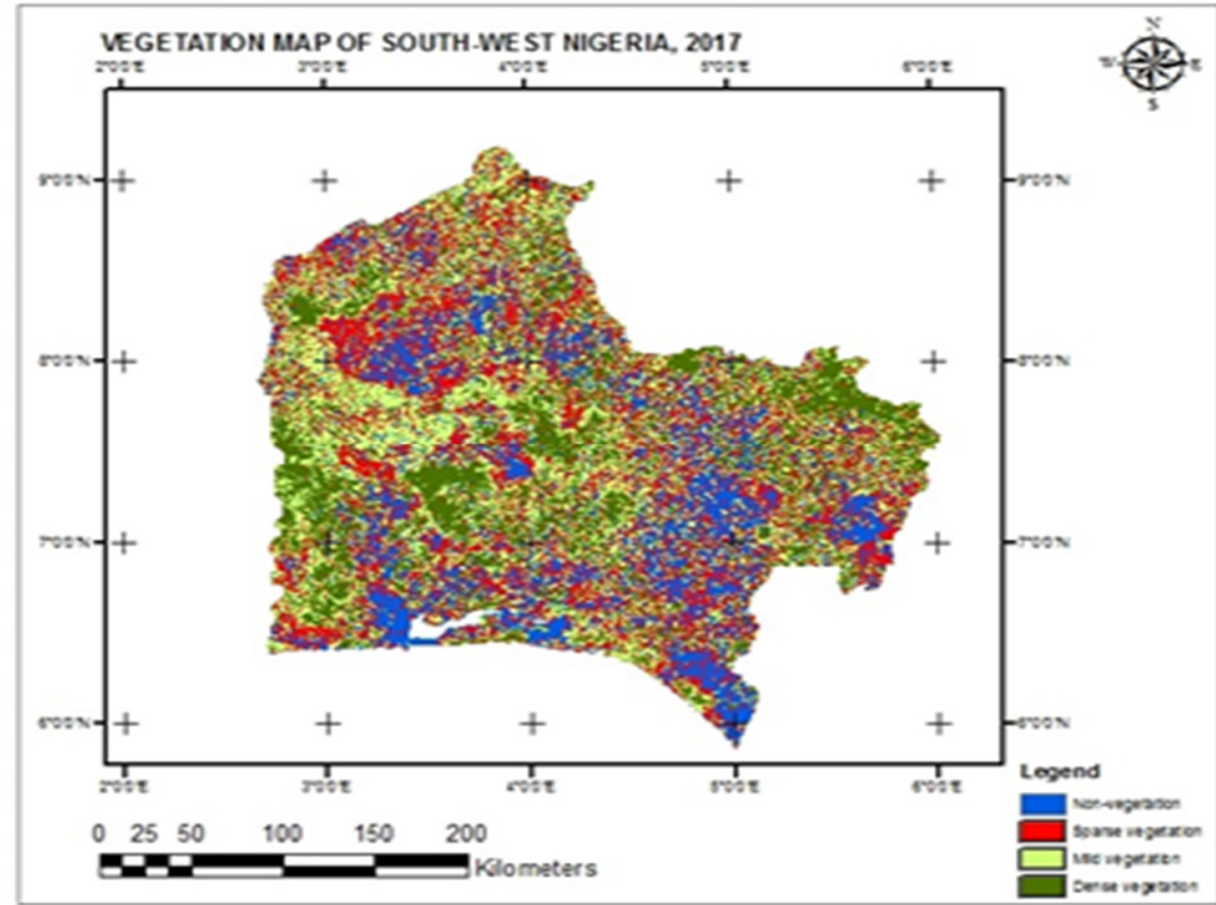

Figure 5: Vegetation map of South-West Nigeria, 2017.

The statistical information showing the aerial extent (in hectares) and the percentage coverage of each vegetation class in the study is presented in Table 1 and Figure 6.

Table 1: Areal extent (in Hectares) and percentage coverage of vegetation class

\begin{tabular}{lllllllll} 
Class & 2002 & $\%$ & 2007 & $\%$ & 2012 & $\%$ & 2017 & $\%$ \\
Sparse veg. & 1.18 & 14.96 & 2.10 & 29.66 & 2.45 & 39.33 & 2.42 & 33.70 \\
Mild veg. & 2.62 & 33.20 & 2.27 & 32.06 & 2.27 & 36.44 & 2.76 & 38.44 \\
Dense veg. & 4.09 & 51.84 & 2.71 & 38.28 & 1.51 & 24.24 & 2.00 & 27.86 \\
Total & 7.89 & 100 & 7.08 & 100 & 6.23 & 100 & 7.18 & 100 \\
\hline
\end{tabular}

Source: Field Survey (2018)

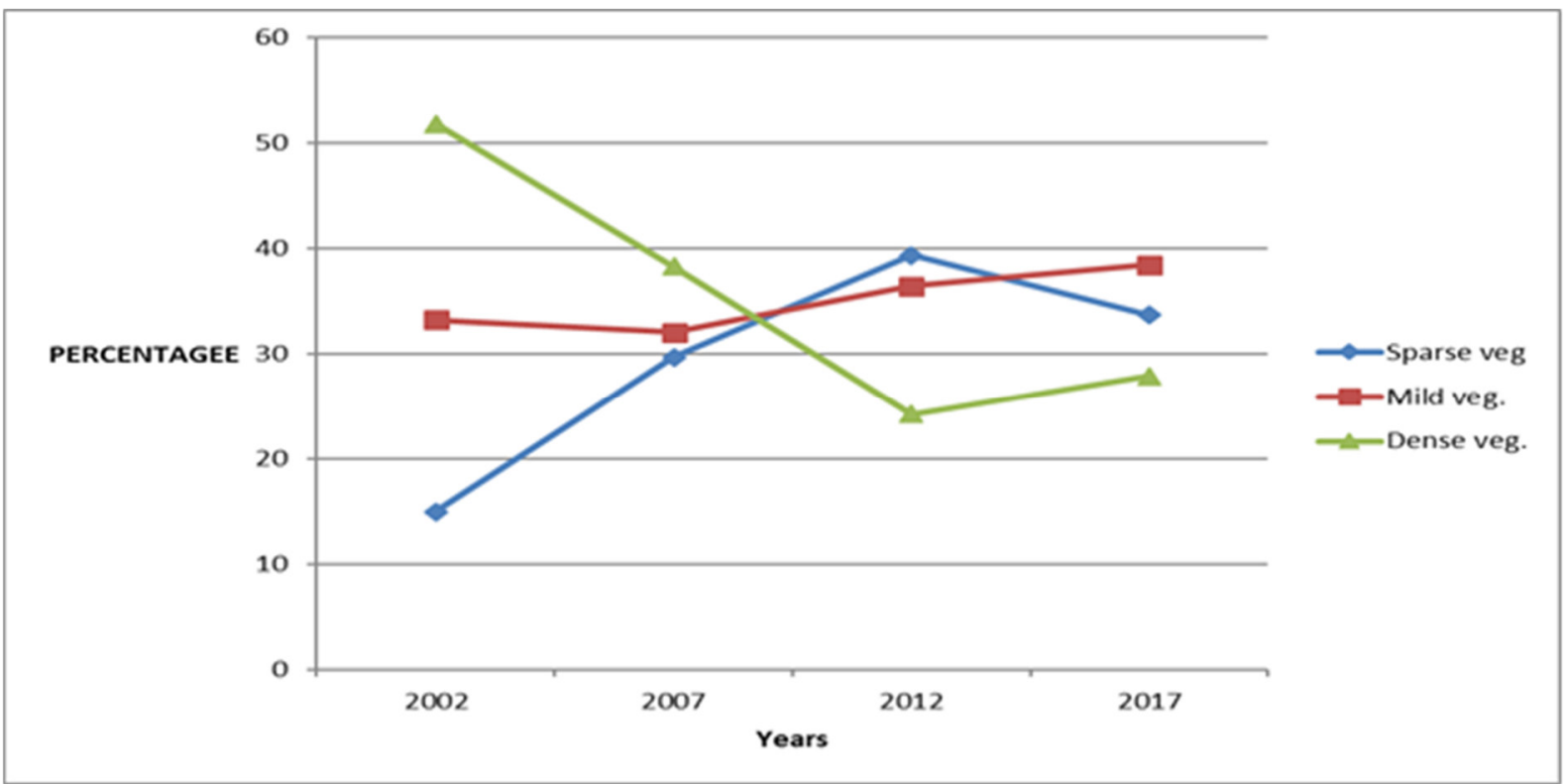

Figure 6: Graph showing Percentage of Vegetation Type Cover vs the Years 


\begin{tabular}{|c|c|c|c|c|c|c|c|c|}
\hline Class & $\begin{array}{l}2002- \\
2007\end{array}$ & $\%$ & $\begin{array}{l}2007- \\
2012\end{array}$ & $\%$ & $\begin{array}{l}2012- \\
2017\end{array}$ & $\%$ & $\begin{array}{l}2002- \\
2017\end{array}$ & $\%$ \\
\hline Sparse veg. & 0.92 & -113.58 & 0.35 & -41.18 & -0.03 & -3.16 & 1.24 & -156.96 \\
\hline Mild veg. & -0.35 & 43.21 & 0.00 & 0.00 & 0.49 & 51.58 & 0.14 & -17.72 \\
\hline Dense veg. & -1.38 & 170.37 & -1.20 & 141.18 & 0.49 & 51.58 & -2.09 & 264.57 \\
\hline Total & -0.81 & 100 & -0.85 & 100 & 0.95 & 100 & -0.79 & 100 \\
\hline
\end{tabular}

\begin{abstract}
Source: Field Survey (2018)
The statistics and trend analyses shown in Tables $1 \& 2$ and Figure 6 indicate that changes of vegetation classes in the period of study were apparent. Sparse vegetation increased by 1.24 hectares (156\%), mild vegetation increased by 0.14 hectares (17.72\%), and dense vegetation reduced by 2.09 hectares $(264.57 \%)$. Moreover, the statistics shows a trend that, sparse vegetation increased progressively from 2002 to 2012, and reduced drastically between 2012 and 2017. For mild vegetation, there was a reduction by 0.35 hectares (43.21\%) from 2002 to 2007 , with a constant area up to 2012, but increased by 0.14 hectares (17.72) in 2017. Furthermore, dense vegetation has experienced more depletion as shown by 1.38 hectares $(170.37 \%)$ reduction from 2002 to $2007,1.20$ hectares (141.18\%) reduction from 2007 to 2012, and 0.49 hectares (51.58) reduction between 2012 and 2017.
\end{abstract}

\title{
5. Conclusion
}

The findings show an apparent depletion in total vegetation in the study area. This is indicative of a parallel increase in sparse vegetation which increased by $156 \%$ in the period under review. Offering a clearer perspective, Oberndorfer and Lundholm (2008) hold that sparse vegetation describes an area of land where plant growth is stunted, and characterized by limited biodiversity. Lending credence, Abis and Brovkin (2017) argue that sparse vegetation is a result of interactions between air temperature, solar radiation, smoke, forest fires, insect outbreaks, to mention a few. This is indicative of a negative impact of industrial projects on the environment under study. It is thus concluded that with the present EIA Act, there is ominous and endemic desertification, deforestation, and global warming in South East, Nigeria, thus making mockery of the country's efforts at sustainable development.

\subsection{Sustainable Development through Going Green-themed EIA for Private Projects in Nigeria}

The term sustainability generally refers to "meeting the needs of the present generation without compromising the needs of future generations." Todaro and Smith (2011) posit that sustainable development is a pattern of development that permits future generations to live at least as well as the current generation. To achieve sustainable development, environmental protection should constitute an integral part of any development process, and not in isolation. It is expected that this would transform our present non-sustainable economic model in a direction consistent with the imperative objectives of sustainable development. By this, going green addresses global concerns by harmonizing economic growth with environmental sustainability in the delivery of industrial projects (Abidin, Yusof and Awang, 2012) through three related concepts of green economy, green growth and low carbon development.

Therefore, the study recommends the inclusion of the going green initiative and sustainable development principles in Nigeria's Environmental Impact Assessment Act. This could be achieved through legislation based on the 3Rs tenet of green economy. The 3Rs principle of reduce, reuse and recycle waste encourages firms to show evidence of techniques they will employ to reduce emission of harmful waste, reuse materials that are not yet disposable, and encourage recycling of waste products. It is also recommended that as a matter of urgency green initiative should be part of the goal and minimum content of EIA report as stipulated in Sections 1 and 4, and also be emphasized in Section 15 (Environmental Assessment Process) as integral part of the follow-up program; with immediate call for generation of a white paper stating necessary modalities.

\subsection{EIA Act Amendment: A Different Approach for Different Outcome}

Nigeria's EIA Act should be amended to imbibe the following:

1. Less use of non-bio-degradable materials in industrial activities, given that these materials distort the natural cycles in the environment, thereby subjecting vegetation and aquatic life to adverse effects.

2. Advocation for a paradigm shift towards the utilization of nanotechnology.

3. Detoxification and controlled disposal of industrial effluents through adherence to the 3 Rs principle of reduce, reuse and recycle.

4. Adoption and use of renewable energy sources, given their more environmentally friendly composition, compared to the heavy air pollution of generators. More so, as there is usually land pollution from use of fossil fuels.

5. Massive capacity building through sensitization workshops and enlightenment of industrialists and other stakeholders on the advantages of going green and utilization of nanotechnology for sustainable 
development.

\section{Practical Implication}

Having shown how combustible industrial activities are to the environment, the paper argues that a green-themed EIA Act would lay solid foundation for the integration of sustainability in industrial activities. By this, significant effort is made to reduce environmental footprints from industrial effluence.

\section{Acknowledgements}

The authors appreciate the selfless assistance of Surveyor Thomas Omali, especially in the collection and analysis of remote sensing data which was very crucial to the success of this study.

\section{References}

Abidin, N.Z., Yusof, N. and Awang, Y.H. (2012). A Foresight into green housing industry in Malaysia. World Academy of Science Engineering and Technology, 6:7, 440-448.

Abis, B. and Brovkin, V. (2017). Environmental conditions for alternative tree-cover states in high lattitudes. Biogeosciences, 14, 511-527

Ajayi, D. (2011). Nigeria's industrial development: Issues and challenges in the new millennium. WIT Transactions on Ecology and the Environment, 150

EIA Decree No. 86 of 1992 now Cap. E12 LFN (2004).

Environmental Impact Assessment Regulations Government Notice No. R.1159 of 2010 of South Africa

EPA. (2018). Guide for industrial waste management. Retrieved from https://www.epa.gov/sites/production/files/2016-03/documents/industrial-waste-guide.pdf, July 1, 2019.

European Commission on Environment (2018). Guidelines on waste prevention programmes. Retrieved from http://ec.europa.eu/environment/waste/prevention/pdf/Waste\%20Prevention_Handbook.pdf on July 1, 2019.

Ewurum, N.I., Okeke, F.I., Ihemeje, I.E., Omali, T. (2018). Environmental Impact Assessment for private industrial projects in South West, Nigeria: Imperatives for going green. Paper presented at the $2^{\text {nd }}$ International Conference of the Department of Geography, University of Nigeria, Nsukka, Enugu, Nigeria.

FORMECU (1998). Forest resource survey. Abuja: Geomatics Nigeria Ltd.

Kutiel, P., Cohen, O., Shoshany, M. and Shub, M. (2004). Vegetation establishment on the Southern Israeli Coastal Sand Dunes between the years 1965 and 1999. Landscape and Urban Planning, 67:1-4, 141-156.

Lu, D. and Weng, Q. (2007). A survey of image classification methods and techniques for improving classification performance. International Journal of Remote Sensing, 28, 823-870.

Mfitumukiza, D. (2014). Classification and mapping of rangeland vegetation physiognomic composition using landsat enhanced thematic mapper and IKONOS imagery. South African Journal of Geomatics, 3, $259-271$.

National Environmental Policy Act (NEPA) 42 U.S.C. 4321-4347

Ndubuisi-Okolo, P. (2016). Waste management and sustainable development in Nigeria: A study of Anambra State Waste Management Agency. European Journal of Business and Management, 8:17

Oberndorfer, E. and Lundholm, J. (2008). Species richness, abundance, rarity and environmental gradients in coastal barren vegetation. Biodervisty and Conservation, 18:6, 1523-1553

Ochege, F.U. and Okpala-Okaka, C. (2017). Remote sensing of vegetation cover changes in the humid tropical rainforests of Southeastern Nigeria (1984-2014). Cogent Geoscience, 3:1, 307-366.

Okeke, F.I. and Omali, T.U. (2016). Spatio-temporal evaluation of forest reserves in the Eastern Region of Kogi State using geospatial technology. Tropical Environment, 13, 75-88.

Omali, T.U. (2018). Impacts of sensor spatial resolution on remote sensing image classification. Global Scientific Journal, 6, 63-68.

Razali, M., Zainudin, Z. and Mei, J. (2017). Sustainable property development by Southeast Asian property companies. Property Management, 35:1, 109 - 126

Saini, R. and Ghosh, S.K. (2018). Exploring capabilities of Sentinel-2 for vegetation mapping using random forest. Paper presented to the International Archives of the Photogrammetry, Remote Sensing and Spatial Information Science, XLII-3, 2 ISPRS TC III Mid-term symposium "Developments, Technologies and Applications in Remote Sensing", Beijing, China, May.

UN (2016). Green economy initiative. Retrieved from http://www.unsceb.org/content/green-economy-initiativegei, July 18, 2019.

Wood, E.M., Pidgeon, A.M., Radeloff, V.C. and Keuler, N.S. (2012). Image texture as a remotely sensed measure of vegetation structure. Remote Sensing Environment, 121, 516-526. 